\title{
The Crohn's and Colitis Foundation of Canada: A time for reflection and strategic planning for the future
}

\author{
Kevin Glasgow MD MBA MHSc FCFP FRCPC ${ }^{1}$, Stephen Vanner MSc MD FRCPC ${ }^{2}$, Senior Associate Editor
}

$\mathrm{D}_{\mathrm{r}}^{\mathrm{r}}$ Kevin Glasgow is the Chief Executive Officer (CEO) of the Crohn's and Colitis Foundation of Canada (CCFC). A community medicine (public health) specialist and family physician by background, he has served in senior leadership positions at the local, provincial and national levels. In addition to both public and private sector health experience, he has served on nonprofit boards, including Habitat for Humanity Toronto (Ontario), the Association of Local Public Health Agencies and the Canadian Institutes of Health Research (CIHR) Institute for Infection and Immunity. He continues to practise clinical medicine part-time.

SV: What is the mission of the CCFC?

KG: The CCFC is a nonprofit organization dedicated to finding a cure for inflammatory bowel disease (IBD), which affects nearly 200,000 people in Canada alone. To realize this, the CCFC is committed to raise increasing funds for medical research, and administers the Inflammatory Bowel Disease Research Institute (IBDRI). The CCFC also believes in educating IBD patients, their families, health professionals and the general public about these diseases.

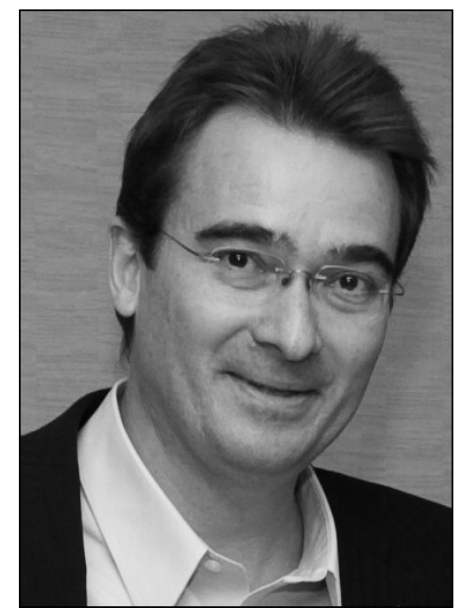

Dr Kevin Glasgow is the Chief Executive Officer of the Crohn's and Colitis Foundation of Canada colitis, as well as robust epidemiological analyses and biomedical discoveries.

I like to say the following in my public speaking appearances: "Along the path to cure - the hope, our ultimate goal the body of scientific knowledge informed by IBD research contributes to better therapies for those affected in the here and now - the cope. The Crohn's and Colitis Foundation of Canada is all about hope and cope."

SV: What are some of the important CCFC initiatives that are currently underway?

KG: Recently, the CCFC committed \$5.5 million to the Michael J Howorth Genetics, Environmental and Microbial (GEM) project. This prospective IBD study is the largest of its kind in the world, and involves the recruitment of 5000 siblings, aged six to 35 years, of persons affected by Crohn's disease. These siblings will be followed forward in time for five years, and comparisons will be made (via questionnaires, biological samples, etc) between persons who develop Crohn's disease (estimated to be 75 in this at-risk population) and matched controls. It is hoped that the study design and sample size will shed new light on the complex interaction among genetics, environmental exposures and microbes involved in the etiology of Crohn's disease. Fourteen collaborative gastroenterology centres from St John's (Newfoundland) to Vancouver (British Columbia) are involved; the principal investigator is Dr Ken Croitoru, with Drs Paul Moayeddi, Anne Griffiths and Mark Ropeleski rounding out the executive team. This study has the potential to become the 'Framingham' of IBD research, and certainly it is probable that it will continue beyond the initial five years.

Another important initiative at the CCFC is the strengthening of the CCFC IBDRI. We have hired a full-time Executive Director of Research and Scientific Liaison, Dr George Tolomiczenko. Dr Tolomiczenko's time will be dedicated to forging partnerships to build IBD research capacity, knowledge translation (which is so important in having the donating public understand the benefits of their donated monies), and assisting me and the volunteer leadership of the IBDRI Executive Council in discerning important research directions in need of funding. In connection with this latter point, the CCFC will significantly advanced the frontiers of medical research, including gene identification for Crohn's disease and ulcerative

${ }^{1}$ Crohn's and Colitis Foundation of Canada, Toronto; ${ }^{2}$ Queen's University, Kingston, Ontario

Correspondence and reprints: Dr Kevin Glasgow, Crohn's and Colitis Foundation of Canada, 600-60 St Clair Avenue East, Toronto, Ontario

M4T 1N5. Telephone 416-920-5035 ext 211, fax 416-929-0364, e-mail clo jwilson@ccfc.ca

Received for publication June 18, 2008. Accepted June 19, 2008 


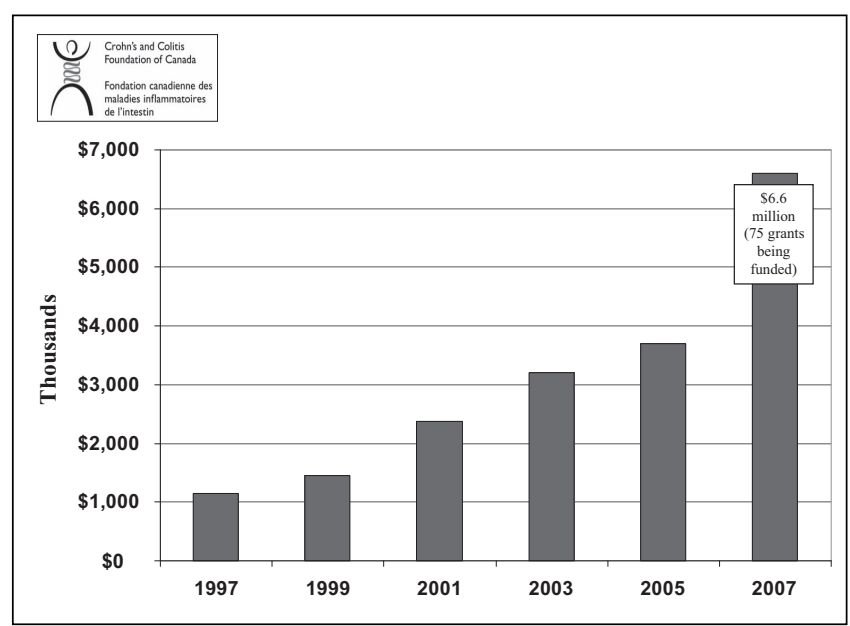

Figure 1) The Crohn's and Colitis Foundation of Canada's annual inflammatory bowel disease research investments (alternate years 1997 to 2007)

be hosting the CCFC's international conference, IBD 2009, next spring as a continuation of our periodic research strategy consultations.

Strategic planning is also very much in the forefront of activity at the CCFC. The CCFC Board of Directors has launched a formal strategic planning process for the overall organization (including volunteerism, fundraising and IBD awareness-raising). The overall strategic plan for the CCFC will be in place in early 2009, and will set the framework in which IBD 2009 will be conducted in terms of focusing on specific research strategies.

SV: You have held a number of other leadership positions in the scientific community in the past. How will these influence your role at the CCFC?

KG: My past career as a public health physician and epidemiologist, as well as a family physician, has contributed to my excitement about being offered a leadership position with the CCFC and, by extension, with the IBD research community. I have treated patients with IBD as a clinician, and I have been a vigorous advocate for sound public policy as a former medical officer of health and a government civil servant. As CEO of the Cardiac Care Network of Ontario for some five years, I worked with cardiologists and cardiac surgeons to facilitate cardiovascular research as well as reduce cardiac procedure wait times. My experience in the wait time field is something I would like to leverage in conjunction with the gastroenterology community as we look at reducing wait times in the gastrointestinal area.

As a former associate vice-president of a major pharmaceutical firm and CEO of a startup biotechnology company, I have learned a great deal about the therapeutic development cycle and the importance of building research capacity. I will apply these learnings, along with my experience as a former Institute Advisory Board member of the CIHR, toward working closely with the Canadian and international research communities to further accelerate our quest for a cure for IBD. My experience as a field site co-coordinator for the Azithromycin in Control of Trachoma study in West Africa (in conjunction with the London School of Hygiene and Tropical Medicine [London, United Kingdom] and the British Medical Research Council) has also equipped me with insights into the running of multicentre intervention trials.
SV: What changes have occurred at the CCFC since you have assumed your position and how do you think they will help the foundation?

KG: Since I assumed my role as CEO of the CCFC in the summer of 2007, the Foundation has been reorganized to better serve our volunteer base and grassroots supporters, including the research community. Some of these changes include the hiring of a full-time Director of Communications, John Branton, whom we recruited from the Juvenile Diabetes Research Foundation Canada to improve our communication with various stakeholder communities. This position will play a leadership role, in conjunction with our Executive Director of Research and Scientific Liaison, in communications to the scientific community (including Gut Reaction, our publication for professional members), as well as in research knowledge translation. We have also undertaken measures to improve the language in our research funding letters to researchers to include language around the 'social contract' of researchers to assist the CCFC by demonstrating the importance and outcomes of their research to the donor community. This includes, for example, the desirability for CCFC-funded researchers to give presentations to CCFC Chapters and other volunteer groups at a certain minimum frequency on request. While many of our funded researchers have admirably performed this function in the past, it is clear that we collectively need to better leverage the ambassadorial potential of our research community to ensure that the virtuous cycle of investment in IBD research reaches its full potential.

Another important forward direction for the CCFC is our evolving role in advocacy directed at getting IBD incorporated as part of national and provincial chronic disease agendas. CCFC staff and volunteers are in the process of liaising with various ministries of health and government agencies to raise awareness about the importance of IBD and to request participation in future consultation processes and steering committees.

Another form of advocacy that is being invigorated at the CCFC is outreach to IBD clinicians beyond our traditionally funded researchers. In the year to come, we will be revising and updating our patient and family education materials, and our hope is to have these materials placed in the offices of every IBD clinician across the country. Finally, the CCFC will be more active in promoting November as IBD awareness month, which was recently proclaimed by the federal Minister of Health. Stay tuned in the months to come for the release of the CCFC's Economic Burden of Illness Report on IBD, which will serve as a vehicle to highlight the importance of considering IBD in research and health care funding decisions.

SV: What challenges do you see as you look ahead?

KG: Our shared challenge in the IBD research community is to sustain the support of our donor base, given that the process of finding a cure for IBD is a mid- to long-term undertaking. Like many other medical research foundations, we need to become more effective communicators at demonstrating the value of our funded research and progress along the path to a cure. Another challenge - which I prefer to look at as an opportunity - is facilitating research coordination across multiple IBD research centres should a particular avenue toward a cure show significant promise. The early promise of the GEM project in terms of coordinating efforts across 14 Canadian gastroenterology research centres is a model that we should be looking at emulating, both in Canada and across international boundaries. The potential to foster Canadian-international 
research collaboration is an opportunity to effectively grow the IBD research pie. A recent example of this was the CCFC's and the Crohn's and Colitis Foundation of America's costshared IBD Environmental Symposium held in Toronto in 2007 (the proceedings of which will soon be published). Another example of international research cross-fertilization is the CCFC Visiting Scientist program.

SV: How would you like to address these?

KG: To promote enhanced intranational and international IBD research collaboration, we will need to build on the culture of collaboration that already exists among Canadian scientists. One of the reasons that Canada is currently a leader in the IBD research field relates to the degree of information sharing that already occurs in Canada. We also need to strike an appropriate balance between investigator-initiated research and strategic direction setting. In much the same fashion as the Medical Research Council of Canada transitioned into the CIHR, fostering of strategic initiatives is something that should occur both on the domestic and international fronts. This is why IBD 2009 and related CCFC research planning activities are so important. The input of Canadian and international IBD research leaders is vitally important to informing this process. A further challenge/opportunity that the CCFC will be addressing is reaching out to other 'nontraditional' potential research partners to find shared causes in funding and research agendas. For example, given the high prevalence of arthritis and related arthritides in persons with IBD, it is conceivable that joint research undertakings could be taken with the rheumatology research community. These are the sort of 'leverage' opportunities our full-time Executive Director of Research and Scientific Liaison will explore, in conjunction with our Institute advisors.

SV: How can the gastroenterology community help?
KG: The gastroenterology community has played, and will continue to play, a vital role in assisting the CCFC in determining effective research investment decisions. Some five years ago, through input received through the CCFC's international conference, IBD 2002, the CCFC transitioned its former Medical Advisory Committee into the CCFC IBDRI, modelled after the CIHR virtual institute model. The input from the gastroenterology community, both scientists and clinicians, is vital for taking the IBDRI to the next level of its evolution. Knowledge translation, awareness-raising and advocacy are activities that the CCFC and the Canadian gastroenterology community should be working increasingly hand-in-hand on. The gastroenterology community, and the larger clinical and research communities, can also assist the CCFC in ensuring that best research funding practices policies continue to be implemented by the CCFC. This includes optimizing our research granting processes and our vitally important peer-review program. Another area in which the gastroenterology community can help further the cause of IBD research and IBD awarenessraising is to work in conjunction with the CCFC's regionally based staff at the local level. This means participation in local chapter, volunteer and fundraising events. The presence of a scientist or clinician at such events means a world of difference to grassroots supporters. Physicians can also talk to their patients and encourage them to seek out the CCFC, both as an information resource and as a volunteer opportunity.

In conclusion, I am very excited at the prospect of further growing research investment in the IBD field. Such opportunities will be fully realized by strengthening the connections between the CCFC and the gastroenterology community. I invite all of you to visit our Web site at <www.ccfc.ca $>$ to learn more about the CCFC both in terms of research involvement and other ways to become involved. 


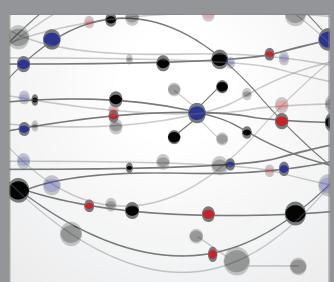

The Scientific World Journal
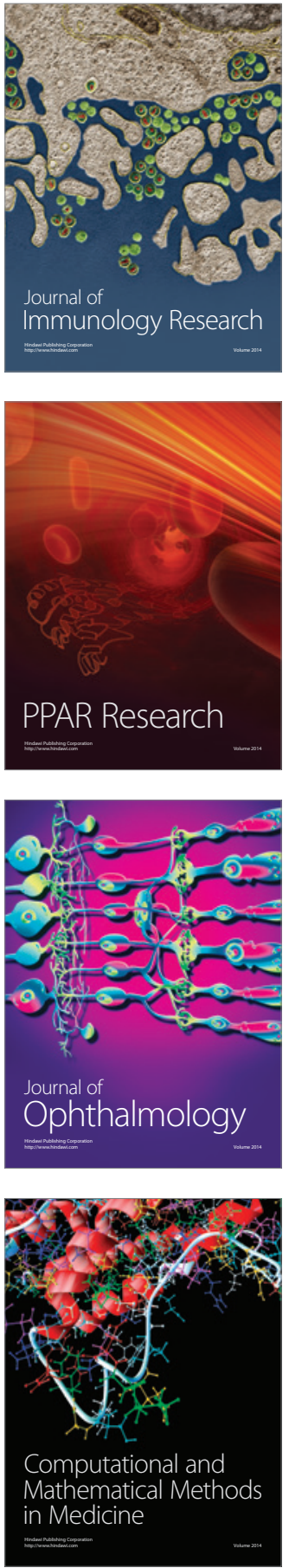

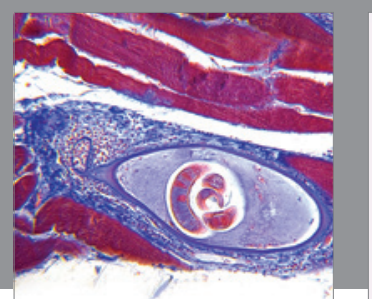

Gastroenterology Research and Practice

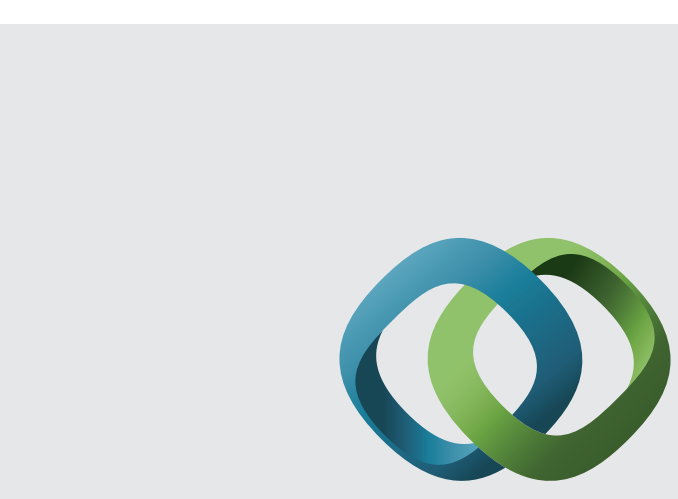

\section{Hindawi}

Submit your manuscripts at

http://www.hindawi.com
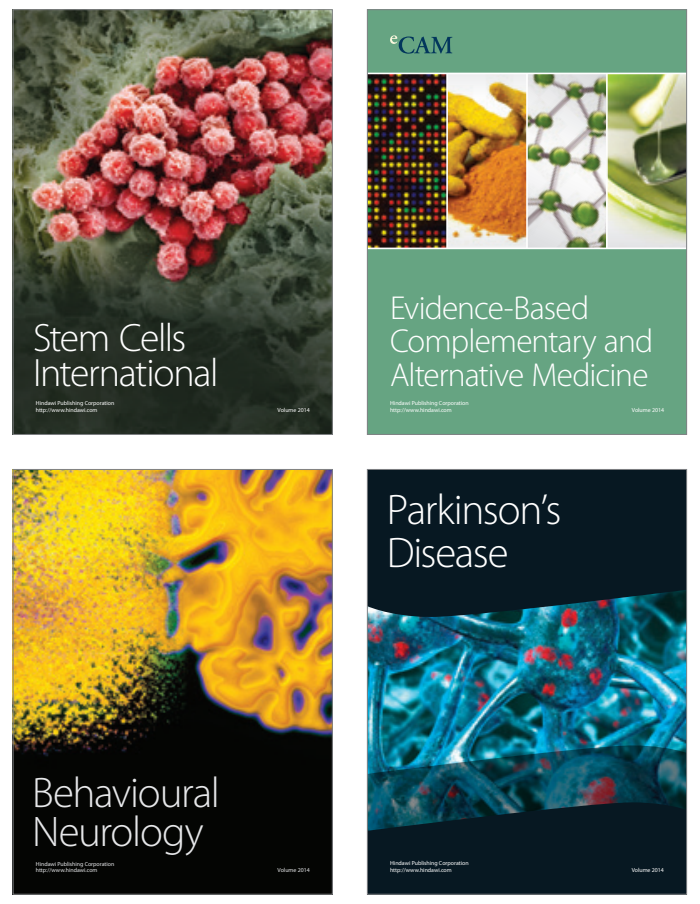
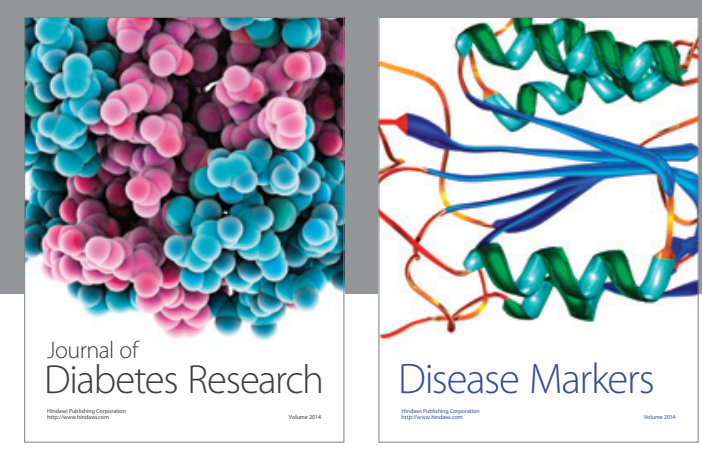

Disease Markers
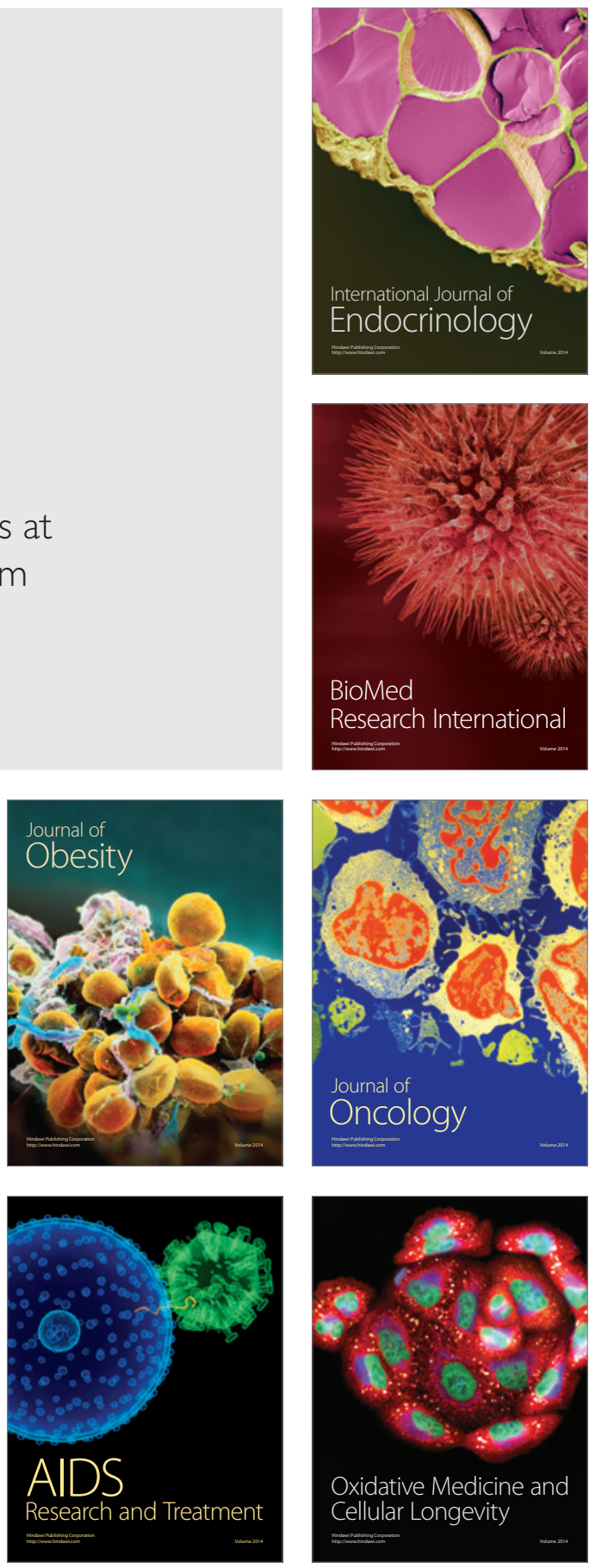